\title{
On the chemical properties of ruthenium and some of its compounds
}

\author{
Dr. C. Claus
}

To cite this article: Dr. C. Claus (1846) On the chemical properties of ruthenium and some of its compounds, Philosophical Magazine Series 3, 29:197, 556-563, DOI: $10.1080 / 14786444608645562$

To link to this article: http://dx.doi.org/10.1080/14786444608645562

册 Published online: 30 Apr 2009.

Submit your article to this journal $[\pi$

Џ Article views: 3

Q View related articles $\asymp$ 
to dry air, behaved like crystals recently taken from their locality.Journ. de Pharm. et de Ch., Septembre 1846.

\section{ANALYSIS OF HEULANDITE. BY M. DAMOUR.}

The difference between the analyses of this mineral by MM. Walmstedt, Thomson and Rammelsberg, consists in the presence of a small quantity of soda and potash. The analysis of Damour gave

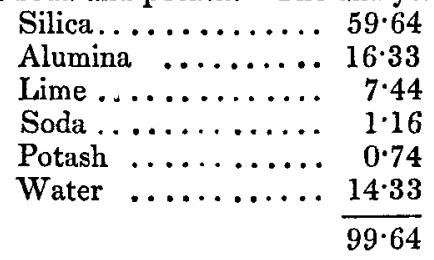

This composition indicates that heulandite should be ranked with zeolites.-Journ. de Pharm. et de Ch., Septembre 1846.

\section{EASY REDUCTION OF CHLORIDE OF SILVER.}

M. Levol states that this chloride is decomposed by being boiled in a solution of potash in which a little sugar is previously dissolved; the sugar gradually reduces the metal in a short time, carbonic acid gas being disengaged : after due washing the metal is obtained in the pulverulent state.-Journ. de Ch. Méd., Novembre 1846.

\section{ON THE CHEMICAL PROPERTIES OF RUTHENIUM AND SOME OF ITS COMPOUNDS. BY DR. C. CLAUS.}

Ruthenium occurs in the residues of the Russian and also of the American platinum ores, but only to the small extent of $1-1 \frac{x}{2}$ per cent. It is a constituent of osmium-iridium; the varieties of this mineral analysed by me contained, besides osmium and iridium, $3-6$ per cent. ruthenium, 10 per cent. platinum, $1 \frac{1}{2}-2$ per cent. rhodium, with traces of copper, iron and palladium. The mineral described by Herman under the name of irite contains 3 per cent. Ru along with $\mathrm{Rh}, \mathrm{Pt}, \mathrm{Os}, \mathrm{Ir}, \mathrm{FeO}, \mathrm{Cr}^{2} \mathrm{O}^{3}, \mathrm{Al}^{2} \mathrm{O}^{3}, \mathrm{SiO}^{3}$ and $\mathrm{IrO}^{2}$. The ruthenium does not occur in that portion of the platinum ore which is soluble in aqua regia; it was discovered in the platinum residues, because these always contain osmium-iridium.

The following is the method which I adopt at present for its preparation:-Osmium-iridium is powdered as finely as possible in a cast iron mortar; the particles of iron removed from the mortar are extracted with muriatic acid, and the powder mixed with chloride of sodium treated at a faint red heat with moist chlorine gas. The decomposed mass is extracted with cold water, and a few drops of ammonia added to the concentrated brownish-red, almost opake solution, which is then heated in a porcelain dish. A voluminous blackish-brown precipitate, consisting of sesquioxide of ruthenium and oxide of os- 
mium, is thrown down. This, after edulcoration, is heated in a retort with a sufficient quantity of nitric acid until the acid has passed over, and the osmium removed as osmic acid. The residue in the retort is removed, ignited with nitre and caustic potash which is free from silica, in a silver crucible, for an hour, and the ignited mass softened and dissolved in cold distilled water. The solution is left to clear for 2 hours in a corked flask, the perfectly transparent, beautiful orange-coloured solution removed with a siphon from the insoluble portion, and the alkaline liquid neutralized with nitric acid; this produces a precipitate of velvety-black sesquioxide of ruthenium, which after edulcoration and drying is reduced in a current of hydrogen. In this way perfectly pure metallic ruthenium is obtained. This mode of separating it from the other platinum metals, with the exception of osmium, is based on the behaviour of the solution of the sesquichloride of ruthenium, which is decomposed by heat into free muriatic acid and sesquioxide. The oxide of osmium is mixed with the oxide of ruthenium, as the solution contains chloride of osmium, which is likewise decomposed. The osmium-iridium is only partially decomposed in the above treatment with chlorine, and must therefore be treated with it three or four times.

Ruthenium thus prepared forms angular pieces, of metallic lustre, which are porous, and very closely resemble iridium. Its specific gravity is very low, viz. 8.6 at $61^{\circ} \mathrm{F}$; but it is highly probable that it is but little inferior in this respect to iridium, for some porous iridium, which was prepared in a similar manner from the blue oxide of iridium IrO\&, had a specific gravity of 9.3 . Ruthenium is very brittle, does not fuse in the Hame of the oxyhydrogen blowpipe, and is almost insoluble in acids ; aqua regia dissolves mere traces of it. After osmium, ruthenium has the greatest affinity for oxygen of all the platinum metals, for it is very readily oxidized on heating to redness. There are four oxides of ruthenium :-

I. The protoxide, $\mathrm{RuO}$, is obtained when 1 equiv. $\mathrm{Ru} \mathrm{Cl} \mathrm{Cl}^{2}$ is heated strongly with rather more than 1 equiv. $\mathrm{NaO} \mathrm{CO}^{2}$ in a current of carbonic acid, and then extracted with water. The protoxide is left as a blackish-gray metallic powder, which is insoluble in acids, and is reduced by hydrogen at the ordinary temperature. It is anhydrous, and contaius in 100 parts $86^{\circ} 6$ ruthenium and 13.4 oxygen. The hydrate is still unknown, and will probably be as difficult to prepare as the hydrate of the protoxide of iron.

II. Sesquioxide, $\mathrm{Ru}^{2} \mathrm{O}^{9}$. Anhydrous.-When the pulverulent metal is exposed to a bright red heat in a platinum crucible over Piclet's glass-blower's lamp, it acquires a black colour, and very quickly absorbs for every 100 parts 18 parts oxygen; subsequently the oxidation slowly proceeds further until the oxide becomes blackish blue, and then contains 23-24 parts oxygen to 100 of ruthenium. This oxide increases still more in weight when exposed to a very long-continued red heat, but it could not be oxidized to RuO?.

The hydrate, $\mathrm{Ru}^{2} \mathrm{O}^{3}+3 \mathrm{aq}$, is obtained by precipitating the sesquichloride with alkalies. It must be well-washed, and nevertheless 
contains a few per cent. of the alkali. It forms a blackish-brown powder, which dissolves with an orange colour in acids, glows suddenly when heated, and is not perfectly reduced at the ordinary temperature by hydrogen. It is insoluble in alkalies.

III. Oxide of Ruthenium, $\mathrm{RuO}^{2}$. Anhydrous.-On roasting and igniting $R u S^{2}$, a blackish-blue powder, with a greenish play of colours, is obtained, which is insoluble in acids, and contains 30.7 parts oxygen to 100 of metal. It is obtained when $\mathrm{RuO}^{\circ}, 2 \mathrm{SO}^{3}$ is exposed to a strong red heat in small grayish particles of metallic lustre, and with a beautiful blue and green iridescence.

The hydrate, $\mathrm{RuO}^{2}+2 \mathrm{aq}$ ?, has not yet been analysed, but it will undoubtedly possess the above composition; it is obtained as a gelatinous yellowish-brown precipitate, when the sclution of the double chloride $\mathrm{KCl}^{2}+\mathrm{RuCl}^{4}$ is mixed with $\mathrm{NaO} \mathrm{CO}$, and evaporated. It contains much alkali, dissolves with a yellow colour in acids, and these solutions become of a rose-red on evaporation. When heated in a platinum spoon it detonates with a lively incandescence, and is projected in all directions. In the dry state it has the colour of impure oxide of rhodium.

IV. Ruthenic acid, $\mathrm{RuO}^{3}$, is not yet known in its isolated state. It is most probably a very unstable compound, which is readily decomposed into oxide and oxygen. It occurs as basic rutheniate of potash in the solution of the ruthenium which has been ignited with potash and saltpetre. The composition of the acid was ascertained in the same way as $\mathrm{H}$. Rose analysed the ferrate of potash. For the analysis however a rutheniate of potash was employed, which had been prepared by igniting the metal with potash and chlorate of potash. The salt could not be obtained crystallized, as the solution is readily decomposed. The solution is of a beautiful orange colour, is very astringent to the taste, like tannic acid, and is neutral, if too much potash and nitre has not been used in its prepara. tion; it colours organic substances black, owing to a deposition of reduced oxide. Acids immediately precipitate from it a black oxide, which contains potash if the solution had not been perfectly neutralized with acid; with a slight excess of acid however the precipi-s tated oxide contains some per cents. of acid. When sulphuric acid is used, a metal is obtained on reducing the oxide which contains some sulphuret, and which it is very difficult to decompose at a faint red heat in a current of hydrogen. I analysed the oxide containing acid, especially that precipitated by nitric acid, and obtained results which led me to believe that this oxide was $\mathrm{RuO}^{-}+2 \mathrm{aq}$ (I was not then acquainted with the true hydrated oxide); but it is very probable that, on igniting it in a current of carbonic acid in order to determine the water, the sesquioxide is converted by the action of the nitric acid into oxide. At present I consider this black oxide to be a hydrate of the sesquioxide, because it dissolves in muriatic acid, forming sesquichloride*.

* Before I was acquainted with the true oxide and perchloride, I thought that muriatic acid converted the black oxide with reduction into sesquichloride, especially as some chlorine was disengaged in the experiment. 


\section{Chlorides of Ruthenium.}

I. Protochloride of Ruthenium, $\mathrm{RuCl}$.-In my former experiments it appeared to me as if ruthenium were little acted upon by chlorine. I subsequently observed however that after very long-continued treatment the metal was converted at a faint red heat into protochloride. When ruthenium is heated to redness in the bulb of a reduction-tube over an Argand lamp, and dry chlorine passed over it, yellow vapours (probably the highest and most volatile chloride) are first disengaged and carried away by the current of gas; the metal seems not to change and to increase in bulk; subsequently some sesquichloride sublimes, and the metal becomes black; after 2 hours it is converted into a black partially crystalline protochloride. It is however not always possible to saturate the ruthenium perfectly with chlorine in one operation; it is best to reduce the protochloride formed to a fine powder, and to treat it again with chlorine. In this way a combination is always obtained, yielding on analysis numbers corresponding to the above formula. Water removes a trace of sesquichloride from it; otherwise it is insoluble in it and in acids; a solution of caustic potash has little action upon it even when evaporated with it to dryness.

Soluble Protochloride.-When the solution of the sesquichloride is treated for a long time with sulphuretted hydrogen, a black-brown sulphuret is precipitated, and the liquid acquires the well-known beautiful azure-blue colour. The sulphuretted hydrogen can be removed from this fluid by a current of atmospheric air, and in this way a solution of the blue protochloride with muriatic acid obtained. I regard this blue combination as the protochloride, although I cannot vouch for the correctness of this view; for it is not possible to prepare it in a solid form or as a crystalline double salt, as it is very readily decomposed, and passes into the orange sesquichloride. I therefore attempted to obtain an idea of the composition of this compound by precipitating the solution of the blue protochloride by alkalies; but the oxide thus obtained possessed the composition of sesquioxide $\mathrm{Ru}^{2} \mathrm{O}^{3}$. This negative result is no direct proof against my view, for I have observed that, in the decomposition of the lower chlorides of iridium by alkalies, the higher oxide $\mathrm{IrO}^{2}$ is constantly formed. Ruthenium must behave similarly, as it exhibits a greater affinity for oxygen than that metal. The reasons which have led me to regard the blue compounds as the protochloride are,-lst, $H S$, in its action upon the perchlorides of the other platinum metals, converts them into lower chlorides; 2nd, the sulphuret which separates on the formation of the blue compound does not contain, as it should, 3 atoms of sulphur to 2 of metal, but 2 and more atoms of sulphur to 1 atom of metal; 3rd, other reducing agents, as zinc, percyanide of mercury, \&c., colour the sesquichloride blue; 4 th, on heating the evaporated solution of the sesquichloride, it becomes green (a mixture of blue and yellow protochloride), and at some spots blue; but it is not possible to prepare in this manner a pure blue protochloride, because a portion of the salt is converted into a basic compound. 
II. Sesquichloride of Ruthenizm, $\mathrm{Ru}^{2} \mathrm{Cl}^{\text {s }}$, is obtained by dissolving the sesquioxide, precipitated from the rutheniate of potash, in muriatic acid, and evaporating to dryness. It is deliquescent, has a very astringent non-metallic taste, like tannic acid ; and dissolves, leaving behind the yellow basic compound, with a beautiful orange-red colour in water and spirit. When heated it acquires the abovementioned green and blue colour. One of its most remarkable properties is that its dilute solution is decomposed by heat into free muriatic acid and hydrated sesquioxide. This decomposition takes place likewise at the ordinary temperature in the course of a few days.

Caustic and carbonated alkalies, as well as the tribasic phosphate of soda, immediately produce in the solution of this salt a blackishbrown precipitate of hydrated sesquioxide, which is not soluble in an excess of the precipitant. Some unprecipitated metal is however left in the solution. Solution of borax at first produces no precipitate, but merely decolorizes the solution, which on the application of heat deposits $\mathrm{Ru}^{2} \mathrm{O}^{s}+3 \mathrm{aq}$. Formiate of soda does not reduce the metal, but only decolorizes the solution; the same happens with oxalic acid. Ferrocyanide of potassium at first decolorizes the solution, which subsequently becomes green. Percyanide of mercury colours the solution blue, with formation of a blue precipitate. Nitrate of silver yields a black precipitate, which subsequently turns white, while the liquid becomes rose-red. Chloride of potassium and chloride of ammonium produce dark brown crystalline precipitates only in very concentrated solutions. Sulphurous acid decolorizes the sesquichloride only after long-continued action. Sulphuretted hydrogen produces the above-mentioned blue reaction, with deposition of sulphuret. Sulphuret of ammonium throws down most of the ruthenium from the solution as a blackish-brown sulphuret, which is not perceptibly soluble in an excess of the precipitant.

III. Perchloride of Ruthenium, $\mathrm{RuCl}^{2}$.- This compound is not known in the isolated state; it exists however in combination with chloride of potassium. In the double salt described below it has the rose colour of the salts of the perchloride of rhodium $\left(\mathrm{Rh}^{2} \mathrm{Cl}^{3}\right)$.

\section{Double Salts.}

I. Sesquichloride of Ruthenium and Potassium, $2 \mathrm{KCl}+\mathrm{Ru}^{2} \mathrm{Cl}^{3}$. -From the composition of this salt the atomic weight of ruthenium was ascertained, and found to be identical with that of rhodium. The analyses of the other compounds of ruthenium have fully confirmed this determination. In the crystallized state it is perfectly insoluble in alcohol of 0.863 spec. grav., and possesses in this respect the properties of the double chlorides of all the other platinum metals with potassium and ammonium. When however the salt is in a concentrated solution, alcohol only throws down a portion; when the solution of the salt is mixed with the chloride of any other metal soluble in alcohol, evaporated to dryness, and digested with strong spirit, the salt of ruthenium dissolves in proportion to the quantity of the other soluble chloride. This property is likewise 
possessed by the sparingly soluble double salts of other platinuin metals, among others by the sodiochloride of rhodium. The crystallized sesquichloride of ruthenium and potassium is almost insoluble in a concentrated solution of chloride of ammonium, and $I$ have used this salt in washing the salt of ruthenium, to free it from any admixture of chloride of potassium. This method is far more certain than the employment of spirit, which only removes with difficulty the last traces of that admixture. It is scarcely necessary to observe that the chloride of ammonium must be subsequently extracted with spirit, which however, from the great solubility of the salt, is very readily and quickly effected.

II. Sesquichloride of Ruthenium and Ammonium, $2 \mathrm{NH}^{4} \mathrm{Cl}+$ $\mathrm{Ru}^{2} \mathrm{Cl}^{3}$, is very easily obtained by mixing the concentrated solution of the black sesquioxide in muriatic acid with chloride of ammonium, and concentrating by evaporation with the addition of a little nitric acid. The salt cannot be distinguished in form and properties from the potash salt; it leaves, as required by the formula, $32 \cdot 7$ per cent. metal when ignited in a current of hydrogen. Both these salts, although more soluble than $\mathrm{KCl}+\mathrm{IrCl}^{2}$, do not dissolve easily in the crystallized state in water; notwithstanding they crystallize with difficulty from their solutions, and only when these are highly concentrated.

III. Sesquichloride of Ruthenium and Sodium ?-This compound could not be obtained crystallized and in a state fit for analysis. It formed a semi-crystalline deliquescent mass, readily soluble in spirit, which dried when strongly heated, but then became partly green and blue, and behaved therefore like a mixture of chloride of sodium and sesquichloride of ruthenium. A solution of chloride of barium and $\mathrm{Ru}^{2} \mathrm{Cl}^{3}$ dried to a deliquescent mass, which resembled the preceding salt, but from which spirit extracted the sesquichloride of ruthenium, leaving behind chloride of barium.

IV. Perchloride of Ruthenium and Potassium, $\mathrm{KCl}+\mathrm{RuCl}^{\circ}$-The conversion of $\mathrm{Ru}^{2} \mathrm{Cl}^{3}$ into $\mathrm{RuCl}^{2}$ is very difficult. When treated for a long time with nitromuriatic acid, only a very small portion passes over into perchloride, and it is impossible to effect its complete conversion. When heated with muriatic acid and chlorate of potash, some of the salt is formed; but the greater portion of the ruthenium is lost, it being converted into a higher chloride (probably $\mathrm{RuCl}^{3}$ ), which is volatile and escapes with the aqueous vapours. I unfortunately did not make this observation before I had already consumed most of the ruthenium, and did not possess sufficient to examine more closely this interesting compound.

I once obtained the perchloride accidentally, having added by mistake too much nitric acid in precipitating the oxide from the rutheniate of potash. The solution of the oxide in nitric acid filtered from the precipitated oxide was brown, and yielded, on evaporation with some muriatic acid, at first a considerable quantity of crystallized saltpetre; and on further concentration of the rosecoloured mother-ley a red salt crystallized, which, washed first with chloride of ammonium, then with spirit, was the compound in its 
pure state. The crystals of this salt are so minute that their form cannot be recognised with the naked eye; with a magnifying power of 300 times diameter they appear as perfectly transparent red prisms with pointed terminal surfaces, probably belonging to the rhombohedral system. The salt is readily soluble in water, insoluble in spirit of 0.889 , and scarcely soluble in a concentrated solution of chloride of ammonium; its solution is of a rose colour playing into violet, and cannot be distinguished from that of the chloride of rhodium and sodium; it is scarcely affected by sulphuretted hydrogen, and only deposits after some time a little yellowish-brown sulphuret, without the liquid losing its red colour. If to the solution of this salt an alkali is added, no precipitate results, but on evaporation a yellowishbrown gelatinous hydrated oxide separates, which contains a considerable quantity of alkali, and when heated on platinum explodes slightly with a sudden glowing. A concentrated solution of this sait in water is only partially precipitated by alcohol; the greater portion remains in solution with a red colour, and is not reduced to a lower chloride on evaporation. The blue reaction of the sesquichloride of ruthenium cannot be produced in the solution of this salt even when sulphuretted hydrogen is passed through it for six hours. The metal reduced from this salt is ruthenium, for it yielded on ignition with nitre rutheniate of potash, and this with muriatic acid sesquichloride of ruthenium, in which the blue reaction could be produced by sulphuretted hydrogen.

\section{Siulphurets.}

It is highly probable that as many combinations of ruthenium with sulphur exist as this metal forms oxides, but their preparation is accompanied with numerous difficulties. When, for instance, powdered ruthenium is mixed with sulphur and heated in an atmosphere of carbonic acid, there is no appearance of any chemical reaction, the sulphur distils off, and the ruthenium increases but little in weight. The precipitates obtained from the chlorides by sulphuretted hydrogen by no means correspond to those compounds; they always contain too much sulphur, and are very probably mixtures of sulphurets with sulphur; their analysis is very difficult, as they easily become oxidized in drying, and are partially converted into sulphate. When heated, in order to remove the water, they explode faintly with incandescence; and when treated with fuming nitric acid, they are likewise oxidized with a faint explosion and a shower of sparks. They dissolve, it is true, in ordinary nitric acid very easily, but the sulphuric acid formed cannot be precipitated pure from this solution by a salt of baryta; it is coloured yellowish, and always contains some sulphate of ruthenium, which cannot be removed by any solvent. When the sulphuret precipitated from the sesquichloride is heated in a reduction-tube through which carbonic acid is passed, water and sulphur are removed, accompanied by a glowing and explosion, and the blackish-gray metallic powder left yields results which correspond to the formula $\mathrm{Ru}^{2} \mathrm{~S}^{3}$. The sulphuret which is precipitated when sulphuretted hydrogen is passed 
for a short time through the solution of $\mathrm{Ru}^{2} \mathrm{Cl}^{3}$, frequently contains 3 atoms of sulphur to 1 of ruthenium; but if the gas has been passed through for several hours, a sulphuret, $\mathrm{RuS}^{2}$, of yellowish-brown colour, is obtained. Sulphuret of ammovium throws down a blackishbrown sulphuret, $\mathrm{Ru}^{2} \mathrm{~S}^{3}$, from the blue protochloride; however, I place little value on these analyses, as the difficulties render the results very uncertain.

\section{Oxysalts.}

I have little experience on this series of compounds, as their preparation is very difficult, and my material was consumed; I only obtained the sulphate of ruthenium, $\mathrm{RuO}^{2}+2 \mathrm{SO}^{3}$, from the sulphuret, which is formed on treating $\mathrm{Ru}^{2} \mathrm{Cl}^{3}$ with sulphuretted hydrogen by oxidizing it with ordinary nitric acid. An orange-coloured solution is obtained, yielding on evaporation to dryness a yellowish brown amorphous mass, which attracts moisture, deliquesces, and has an acid astringent taste. The dry compound reduced to powder resembles mosaic gold, dissolves readily in water, and is not precipitated at first by alkalies; but on evaporation the yellowish-brown gelatinous hydrated oxide separates, which has the greatest resemblance to the impure oxide of rhodium, and explodes with incandescence when heated. Sulphuretted hydrogen does not produce the blue reaction in the solution of this salt.-Liebig's Annalen for August 1846.

\section{ON PHOSPHAM AND PHOSPHAMIDE.}

M. Gerhardt observes that chemists admit of the existence of two compounds of nitrogen and phosphorus; one composed of 1 atom of phosphorus and 2 atoms of nitrogen $\left(\mathrm{PN}^{2}\right)$ is produced, according to M. H. Rose, when the protochloride is heated with ammonia ; according to MM. Liebig and Wöhler it is also formed by the action of heat on the produce of the reaction of ammonia on perchloride of phosphorus.

The other compound of nitrogen and phosphorus has been described by M. Liebig in his Annulen. It is considered by him as a compound of the preceding phosphuret of nitrogen, and the elements of water $\left(\mathrm{PN}^{2}+\mathrm{H}^{2} \mathrm{O}\right)$; it is therefore a hydrated phosphuret of nitrogen.

The composition which is attributed to these two compounds by the German chemists being different from those defended by MM. Gerhardt and Laurent, the former has subjected them to fresh examination, and states as the result that no such compound as phosphuret of nitrogen exists; and that the two bodies improperly so named are mixtures of three definite compounds, one of which he calls phosphamide, containing phosphorus, hydrogen, nitrogen and oxygen; the second, which he names biphosphamide, contains phosphorus, nitrogen and oxygen; and the third, named phospham, consists of phosphorus, nitrogen and hydrogen.

Phosphamide.-When gaseous ammonia is passed over perchloride of phosphorus contained in a long tube, the chloride becomes considerably heated, fuses, gives out much hydrochloric acid gas, and produces much hydrochlorate of ammonia. The product obtained 